\title{
Suppression of Akt-HIF-1 $\alpha$ signaling axis by diacetyl atractylodiol inhibits hypoxia-induced angiogenesis
}

\author{
Sik-Won Choi, ${ }^{1, \#}$, Kwang-Sik Lee ${ }^{1,2, \#}$, Jin Hwan Lee ${ }^{3}$, Hyeon Jung Kang ${ }^{1}$, Mi Ja Lee ${ }^{1}$, Hyun Young Kim ${ }^{1}$, Kie-In Park ${ }^{4}$, \\ Sun-Lim Kim ${ }^{1}$, Hye Kyoung Shin ${ }^{5, *}$ E Woo Duck Seo, \\ ${ }^{1}$ Division of Crop Foundation, National Institute of Crop Science (NICS), Rural Development Administration (RDA), Wanju 55365, \\ ${ }^{2}$ College of Crop Science and Biotechnology, Dankook University, Cheonan 31116, ${ }^{3}$ Division of Research Development and Education, \\ National Institute of Chemical Safety, Ministry of Environment, Daejeon 34111, ${ }^{4}$ Division of Biological Sciences, College of Natural \\ Science, Chonbuk National University, Jeonju 54896, ${ }^{5}$ Department of surgery, Gangnam Severance Hospital, Yonsei University College of \\ Medicine, Seoul 06273, Korea
}

\begin{abstract}
Hypoxia-inducible factor (HIF)- $1 \alpha$ is a key regulator associated with tumorigenesis, angiogenesis, and metastasis. HIF-1 $\alpha$ regulation under hypoxia has been highlighted as a promising therapeutic target in angiogenesis-related diseases. Here, we demonstrate that diacetyl atractylodiol (DAA) from Atractylodes japonica (A. japonica) is a potent HIF-1 $\alpha$ inhibitor that inhibits the Akt signaling pathway. DAA dose-dependently inhibited hypoxia-induced HIF-1 $\alpha$ and downregulated Akt signaling without affecting the stability of HIF-1 $\alpha$ protein. Furthermore, DAA prevented hypoxia-mediated angiogenesis based on in vitro tube formation and in vivo chorioallantoic membrane (CAM) assays. Therefore, DAA might be useful for treatment of hypoxia-related tumorigenesis, including angiogenesis. [BMB Reports 2016; 49(9): 508-513]
\end{abstract}

\section{INTRODUCTION}

Malignant tumors are poorly oxygenated due to the consumption of available oxygen by fast proliferating cells. Such tumor hypoxia induces specific cellular and systemic adaptive responses, including hypoxia-inducible factor (HIF)-1 pathway responsible for the activation of genes involved in energy metabolism, angiogenesis, and apoptosis (1-7). HIF-1 transcriptionally upregulates over 100 genes. Its overexpression is associated with increased mortality in patients with various

*Corresponding authors. Hye Kyoung Shin, Tel: +82-2-2019-5350; Fax: +82-2-2019-5210; E-mail: hk1028@yuhs.ac, Woo Duck Seo, Tel: +82-63-238-5333; Fax: +82-63-238-5335; E-mail: swd2002@ korea.kr

${ }^{\text {"}}$ These authors contributed equally to this work.

http://dx.doi.org/10.5483/BMBRep.2016.49.9.069

Received 19 April 2016, Revised 7 June 2016, Accepted 18 July 2016

Keywords: Akt-HIF-1 $\alpha$ signaling, Angiogenesis, Diacetyl atractylodiol, HIF-1 $\alpha$, Hypoxia cancers $(8,9)$. Consequently, HIF-1 has been reported to have significant potential as a target for cancer therapy (10-12).

To facilitate continuous growth and proliferation in hypoxic microenvironments, cancer cells alter their metabolisms by angiogenesis. Tumor angiogenesis creates new blood vessels from pre-existing vascular structures. This has been reported in various types of malignant tumors (13). Angiogenesis provides necessary nutrients and oxygen to tumors, making it critical for initial growth, invasiveness, and metastasis $(4,14)$. Several studies have suggested that anti-angiogenic agents can impair tumor growth, metastasis, and mass (15-17). Thus, developing anti-angiogenesis agents is an important therapeutic strategy for cancer $(18,19)$.

The rhizome extract of Atractylodes japonica koidzumi has been used in folk medicine to treat diverse diseases, including rheumatic diseases, digestive disorders, night blindness, and influenza. The major constituents of $A$. japonica possess pharmacological activities including anticancer, anti-inflammatory, antimicrobial, antipyretic, and anti-hypertensive effects (20-23). Diacetyl atractylodiol (DAA) is one of the phytochemical compounds in A. japonica. DAA can stimulate distal colon motility in rats (24). However, whether angiogenesis modulation is involved in the antitumor activity of DAA has not been explored. Therefore, the objective of this study was to determine the effect of DAA on hypoxia-induced angiogenesis and the underlying molecular mechanisms.

\section{RESULTS}

DAA inhibits $\mathrm{CoCl}_{2}$-induced hypoxic situation in HeLa cells We screened approximately 200 natural compounds for their abilities of activing HIF- $1 \alpha$ transcription using a dual luciferase assay-based double readout system consisting of HeLa-hypoxia response element (HRE) with firefly luciferase (FL) and Renilla luciferase (RL). Among these natural compounds screened, DAA had the most potent activity (Fig. 1A). $\mathrm{CoCl}_{2}$, a hypoxia-mimicking agent, also induced significant hypoxiarelated activity. However, DAA treatment dose-dependently

ISSN: 1976-670X (electronic edition)

Copyright (c) 2016 by the The Korean Society for Biochemistry and Molecular Biology

(c) This is an open-access article distributed under the terms of the Creative Commons Attribution Non-Commercial License (http://creativecommons.org/licenses/by-nc/4.0) which permits unrestricted non-commercial use, distribution, and reproduction in any medium, provided the original work is properly cited. 
A

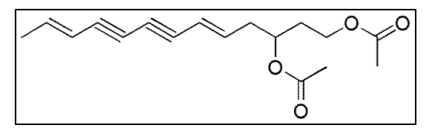

C

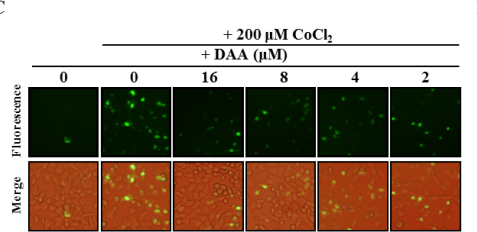

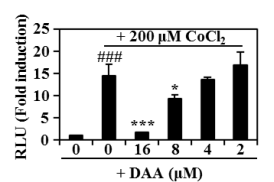

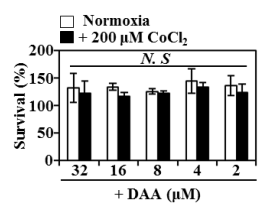

Fig. 1. DAA attenuated $\mathrm{CoCl}_{2}$-induced hypoxia. (A) Molecular structure of DAA. (B) Luciferase activity following DAA treatment after $16 \mathrm{~h}$ of $\mathrm{CoCl}_{2}$ exposure. ${ }^{\# \# \#} \mathrm{P}<0.001$ versus negative control; $* \mathrm{P}<0.05, * * * \mathrm{P}<0.001$ versus positive control. (C) GFP expression of HeLa cells treated with ad-HIF-1 $\alpha$-GFP in the presence of $\mathrm{CoCl}_{2}(200 \mu \mathrm{M})$ for $12 \mathrm{~h}$. (D) Effect of DAA on HeLa cell viability with or without $\mathrm{CoCl}_{2}(200 \mu \mathrm{M})$ was evaluated by CCK-8 assay. NS: not significant.

inhibited the luciferase activity induced by $\mathrm{CoCl}_{2}$ (Fig. 1B). To determine whether DAA inhibited the accumulation of HIF-1 $\alpha$ protein, HeLa cells were infected with adenovirus containing HIF-1 $\alpha$ fused to GFP (adHIF-1 $\alpha-G F P$ ). Based on immunofluorescence results (Fig. 1C and Supplementary Fig. 1), HIF-1 $\alpha$ was translocated into the nuclei by $\mathrm{CoCl}_{2}$. However, DAA treatment strongly inhibited the accumulation and nuclear translocation of HIF-1 $\alpha$. The presence of DAA did not significantly affect the survival of HeLa cells under normoxic or hypoxic conditions, indicating that the inhibitory effect of DAA on $\mathrm{CoCl}_{2}$-induced hypoxia was not due to its cytotoxicity (Fig. 1D). These results suggest that DAA can suppress the effect of hypoxia by inhibiting HIF- $1 \alpha$ accumulation.

\section{DAA inhibits hypoxia-induced transcriptional activity} without affecting HIF-1 $\alpha$ protein degradation

Next, we attempted to clarify whether the inhibition of hypoxia by DAA was mediated by suppression of HIF-1 $\alpha$ expression. Therefore, the expression levels of several hypoxiaassociated genes were determined by real-time PCR. As shown in Fig. $2 \mathrm{~A}, \mathrm{CoCl}_{2}$ strongly induced $\mathrm{HIF}-1 \alpha$ expression. This induction was attenuated by DAA. DAA also strongly inhibited the expression of HIF-1 $\alpha$-dependent genes such as Glut1 and vascular endothelial growth factor (VEGF). Western blot analysis revealed that DAA exposure decreased the protein expression levels of HIF- $1 \alpha$ induced by $\mathrm{CoCl}_{2}$ and $1 \%$ oxygen (Fig. 2B). Next, to assess the effect of DAA on HIF-1 $\alpha$ protein stability, protein translation inhibitor $\mathrm{CHX}$ was used to prevent de novo HIF-1 $\alpha$ protein synthesis. We first induced HIF- $1 \alpha$ accumulation in the presence of $\mathrm{CoCl}_{2}$ for $12 \mathrm{~h}$ followed by $\mathrm{CHX}$ treatment alone or in combination with DAA. As shown in Fig. $2 \mathrm{C}$, in the presence of $\mathrm{CHX}, \mathrm{HIF}-1 \alpha$ levels were rapidly decreased in both DAA-treated and untreated cells. Densitometry
A

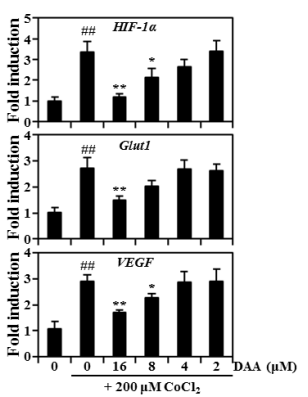

B
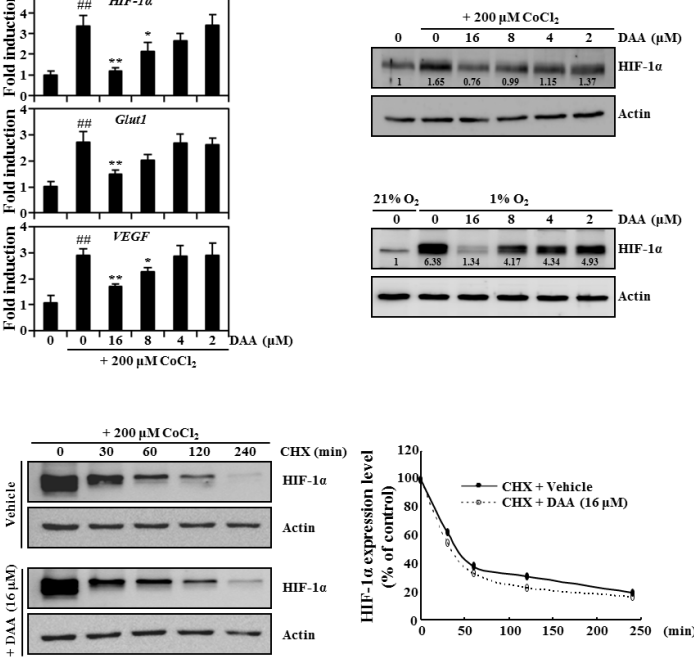

Fig. 2. DAA inhibited hypoxia-induced HIF-1 $\alpha$ mRNA expression. (A) mRNA levels were evaluated by real-time PCR following $16 \mathrm{~h}$ of $\mathrm{CoCl}_{2}(200 \mu \mathrm{M})$ exposure and $1 \mathrm{~h}$ of DAA pretreatment. (B) Effect of DAA on HIF-1 $\alpha$ protein levels was evaluated by western blot analysis after treatment with $\mathrm{CoCl}_{2}$ or $1 \%$ oxygen. Actin was used as an internal loading control. Densitometric analysis was performed using ImageJ software. (C) Immunoblot analysis of HIF-1 $\alpha$ protein levels in HeLa cells exposed to $12 \mathrm{~h} \mathrm{CoCl}_{2}$ followed by treatment with DMSO or DAA $(16 \mu \mathrm{M})$ and $\mathrm{CHX}$ $(100 \mu \mathrm{M})$. Actin was used as a loading control. Relative changes in HIF-1 $\alpha$ protein levels were quantitated by densitometric analysis using ImageJ software.

analysis suggested that both cell groups exhibited similar HIF- $1 \alpha$ degradation kinetics (Fig. 2C, right panel). Combined treatment of DAA and actinomycin D (transcription inhibitor) significantly attenuated HIF-1 $\alpha$ expression (Supplementary Fig. 2). These results indicate that the inhibitory effect of DAA-mediated HIF- $1 \alpha$ expression under hypoxic conditions contributes to the downregulation of HIF- $1 \alpha$ transcription without affecting HIF-1 $\alpha$ protein degradation.

\section{DAA inhibits $\mathrm{CoCl}_{2}$-induced phosphorylation of Akt}

Next, we examined whether DAA affected the activation of $\mathrm{CoCl}_{2}$-induced signaling pathways associated with the regulation of HIF-1 $\alpha$ expression. HeLa cells were pretreated with DAA at various concentrations and stimulated with $\mathrm{CoCl}_{2}$. Our results revealed that $\mathrm{CoCl}_{2}$ strongly induced the phosphorylation of Akt and ERK1/2. However, DAA treatment attenuated Akt phosphorylation in a dose-dependent manner (Fig. 3). Our results suggest that inhibition of Akt phosphorylation contributes to the anti-hypoxic effect of DAA.

\section{DAA attenuates angiogenesis in vitro and in vivo}

Serum-limited HUVECs were stimulated by FGF and EGF with $\mathrm{CoCl}_{2}$ in the presence of DAA or vehicle. DAA significantly 


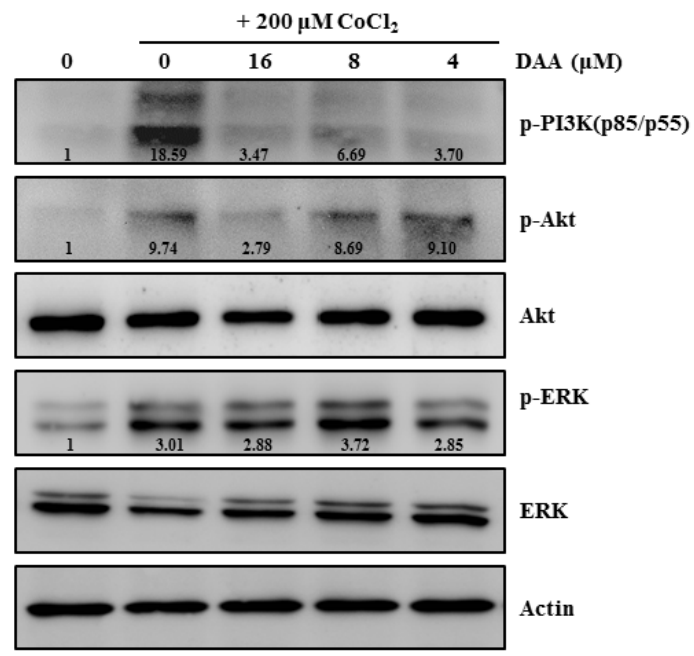

Fig. 3. DAA attenuated $\mathrm{CoCl}_{2}$-induced PI3K/Akt signaling in HeLa cells. The expression of factors associated with signaling pathways following DAA treatment with or without $12 \mathrm{~h}$ of $\mathrm{CoCl}_{2}$ exposure were evaluated by western blotting. Actin was used as a loading control. Densitometric analysis was performed using ImageJ software.

inhibited HUVEC tube formation in a dose-dependent manner (Fig. 4A). Real-time PCR results revealed that DAA attenuated $\mathrm{CoCl}_{2}$-induced HIF-1 $\alpha$ and VEGF transcriptional levels in HUVECs (Fig. 4B). As shown in Fig. 4C, DAA did not exhibit cytotoxicity in HUVECs at the concentrations used. We next evaluated the anti-angiogenic activity of DAA using in vivo chick embryo chorioallantoic membrane (CAM) assay. Normally developed CAM exhibited successful angiogenic response with new capillaries created from the existing vascular network. However, DAA dose-dependently inhibited neovessel formation in chick embryos without showing toxicity or side effects (Fig. 4D). Based on the percentage of eggs with positive anti-angiogenic response, the inhibition rate of new vessels was increased in a concentration-dependent manner (Fig. 4E). These results demonstrate that DAA inhibits angiogenesis both in vitro and in vivo through attenuating HIF-1 $\alpha$ expression.

\section{DISSCUSSION}

In this study, to identify new natural product-based inhibitors of the HIF-1 signaling pathway, we evaluated $\sim 200$ natural products to determine their potentials in reducing HIF- $1 \alpha^{-}$ mediated HRE transcriptional activity using a double readout cell-based assay system. Among the products tested, DAA from A. japonica strongly inhibited hypoxia-induced angiogenesis both in vitro and in vivo. DAA also attenuated HIF-1 $\alpha$ expression through phosphatidylinositol-3-kinase (PI3K)/Akt signaling pathway, suggesting a novel mechanism for its anti-angiogenic effect.
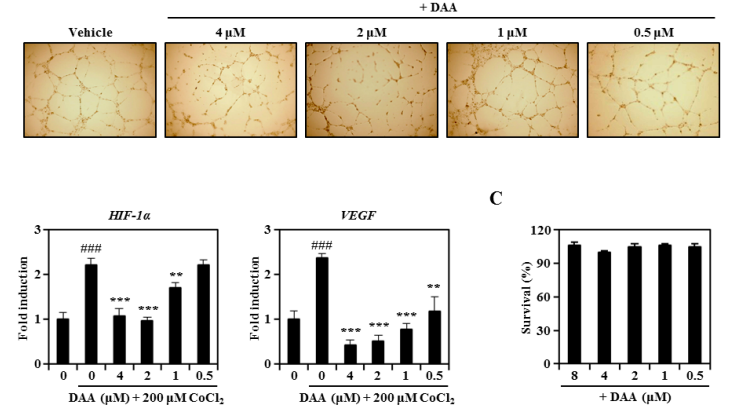

D
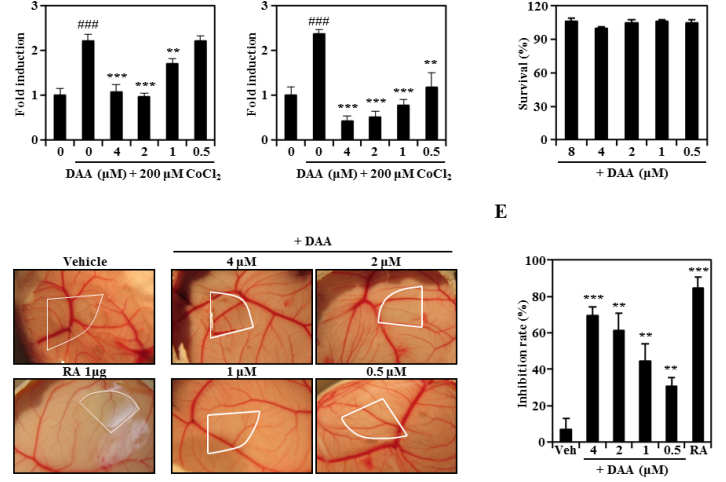

Fig. 4. DAA inhibited angiogenic activity both in vitro and in vivo. (A) HUVECs were cultured with $\mathrm{CoCl}_{2}$ and DAA for $16 \mathrm{~h}$ and visualized under a light microscope. (B) mRNA levels in HUVECs stimulated with $\mathrm{CoCl}_{2}$ and DAA for $16 \mathrm{~h}$ were evaluated by real-time PCR. \#\# P $<0.001$ compared to $\mathrm{CoCl}_{2}$-treated group; $* * \mathrm{P}<0.01, * * * \mathrm{P}<0.001$ compared to the group treated with $\mathrm{CoCl}_{2}$ and DAA. (C) Effect of DAA on HUVEC viability was evaluated by CCK-8 assay. (D) Neovessel formation in CAM assay after 2 days of DAA treatment was photographed with a digital camera. White areas indicate regions of application to the CAM surfaces. (E) Quantitative activities were based on the proportion of eggs with positive anti-angiogenic response relative to the total number of eggs tested. $* * P<0.01, * * * P<0.001$ versus control.

It has been reported that HIF-1-induced glucose transporters (Gluts) are essential for Warburg effect observed in tumor cells (25). HIF-1 transcriptional induction may also play an important role in the regulation of genes related to tumor angiogenesis such as VEGF. VEGF induction stimulates the development of new blood vessels to oxygenate tumor cells (26). In this study, DAA strongly inhibited $\mathrm{CoCl}_{2}$-induced HRE luciferase activity and HIF-1 $\alpha$ transcriptional activity in addition to VEGF and Glut1.

HIF-1 $\alpha$ is involved in activation of PI3K/Akt and extracellular signal-regulated kinase-1 (ERK1) signaling pathways $(27,28)$. Previous studies have demonstrated that hypoxic environments can trigger the activation of PI3K/Akt and ERK that plays a major role in HIF-1 $\alpha$ expression (29-31). PI3K inhibitor LY294002 suppresses TNF- $\alpha$-induced HIF-1a expression in rheumatoid synovial fibroblasts (32). Furthermore, the PI3K/Akt signaling pathway is implicated in VEGF expression in cancer cells and angiogenesis acceleration (33). Our results suggest that DAA inhibits PI3K/Akt-HIF-1 $\alpha$ signaling axis without affecting ERK phosphorylation under hypoxic conditions. 
Hypoxia is a key physiological signal for angiogenesis and HIF-1 $\alpha$ induction in tumors $(34,35)$. Knockdown of the HIF-1 $\alpha$ gene can inhibit the induction of VEGF in hypoxic cells and reduce vascular leakage $(36,37)$. Therefore, HIF-1 $\alpha$ suppression reduces the production of VEGF and inhibits angiogenesis (38). Recent studies have provided evidence on HIF-1 $\alpha$-related resistance to chemotherapy $(39,40)$. The results of this study also indicate that DAA inhibits hypoxiainduced physiological conditions necessary for angiogenesis.

In summary, DAA from $A$. japonica strongly inhibited hypoxia by downregulating HIF-1a expression through a mechanism that may involve PI3K/Akt inactivation. Downregulating HIF-1 transcription activity reduced the transcription levels of VEGF (essential for angiogenesis) and Glut1 (essential for tumor growth). Our results suggest that DAA can be included in functional foods or pharmacological agents for the prevention and treatment of various human cancers. However, further studies are required.

\section{MATERIALS AND METHODS}

\section{Cell culture and reagents}

HeLa cells were maintained in Dulbecco's Modified Eagle's Medium (DMEM, Gibco, Grand Island, NY, USA) containing $10 \%$ fetal bovine serum (FBS, Gibco) supplemented with antibiotics $(100 \mathrm{U} / \mathrm{ml}$ of penicillin and $100 \mu \mathrm{g} / \mathrm{ml}$ streptomycin; Invitrogen Life Technologies, Carlsbad, CA, USA). Human umbilical venous endothelial cells (HUVECs) were grown for 4-8 passages in human endothelial-serum free medium (SFM, Gibco) with 10\% FBS. Hypoxic culture was achieved by treatment with cobalt chloride $\left(\mathrm{CoCl}_{2}\right)$, a hypoxia-mimicking agent, for 12-16 h. In some cases, hypoxic cells were kept in a gas-controlled chamber (Thermo Fisher Scientific Inc., Waltham, MA, USA) at $1 \% \mathrm{O}_{2}, 94 \% \mathrm{~N}_{2}$, and $5 \% \mathrm{CO}_{2}$. DAA was purchased from $\mathrm{ABI}$ Chem (Munchem, Germany) and dissolved in dimethyl sulfoxide (DMSO; Sigma-Aldrich, St Louis, MO, USA). Cycloheximide (CHX) and $\mathrm{CoCl}_{2}$ were obtained from Sigma-Aldrich Co. Hygromycin and puromycin were purchased from Invitrogen Life Technologies. Primary antibodies against phospho-PI3 Kinase p85 (Tyr458)/ p55 (Tyr199), phospho-Akt (Ser473), phospho-p44/p42 MAPK (Erk1/2; Thr202/Tyr204), Akt, and Erk1/2 were purchased from Cell Signaling Technology (Beverly, MA, USA). Antibody against HIF-1 $\alpha$ was obtained from BD Biosciences (San Diego, CA, USA). All other antibodies including those against actin were purchased from Santa Cruz Biotechnology (Dallas, TX, USA).

\section{Stable cell lines and luciferase assay}

The ability of the compound to inhibit HIF was measured using a double readout cell-based assay system with two stable cell lines. The vectors for hypoxia response element (HRE)firefly luciferase $(\mathrm{FL})$ and Renilla luciferase $(\mathrm{RL})$ were obtained from Promega Corporation (Madison, WI, USA). Stable HeLa cell lines were generated by transfection with HRE-FL for hypoxic activity using RL as an internal control. After transfection for $48 \mathrm{~h}$, cells were selected with hygromycin $(150 \mu \mathrm{g} / \mathrm{ml})$ and puromycin $(5 \mu \mathrm{g} / \mathrm{ml})$ for 3 weeks. To measure luciferase activity, a mixture (HRE-FL:RL $=3: 1$ ) of two stable cell lines was plated into 96 -well plates at $4 \times 10^{3}$ cells per well. After $16 \mathrm{~h}$ of incubation, cells were stimulated by $\mathrm{CoCl}_{2}$ and lysed with cell lysis buffer (Promega). Luciferase activity was measured using dual-luciferase assay system (Promega). Luciferase activity was normalized to that of Renilla luciferase. The mean values and standard deviations of triplicate samples are shown.

\section{Adenovirus infection}

HIF-1 $\alpha$-GFP recombinant adenovirus was purchased from Cell Biolabs (San Diego, CA, USA). HeLa cells were infected with HIF- $1 \alpha$ adenovirus at a multiplicity of infection (MOI) of 10 for 6 h. After infection by HIF- $1 \alpha$ adenovirus, cells were incubated with $200 \mu \mathrm{M} \mathrm{CoCl}_{2}$ and the indicated concentration of DAA for $12 \mathrm{~h}$. the cells were fixed with $3.7 \%$ formaldehyde, and GFP expression was photographed under a fluorescence microscope.

\section{Cell viability assay}

HeLa cells were plated into a 96-well plate at $4 \times 10^{3}$ cells/well in triplicates. After treatment with DAA, cells were incubated for 2 days under normoxia or hypoxia mimicking conditions. Cell viability was evaluated using Cell Counting Kit-8 (Dojindo Moleculer Technologies, Rockville, MD, USA) according to the manufacturer's protocol.

\section{Real-time PCR}

Real-time PCR was performed as described previously $(41,42)$. Primers were designed using the online Primer3 software (43). The primer sequences were as follows: Glut1 forward, 5'-TGG ATG TCC TAT CTG AGC ATC G-3'; Glut1 reverse, 5'-CTC CTC GGG TGT CTT GTC AC-3'; VEGF forward, 5'-AAC TTT CTG CTG TCT TGG-3'; VEGF reverse, 5'- TTT GGT CTG CAT TCA CAT-3'; HIF-1 $\alpha$ forward, 5'- ACT TAA GAA GGA ACC TGA TG-3'; HIF-1 $\alpha$ reverse, 5'- TGG AGA CAT TGC CAA ATT TA-3'; HIST3H2A forward, 5'- CTT GAC TCG GAA ATG TCC GGT CG-3'; HIST3H2A reverse, 5'- AGT CAA GTA CTC GAG CAC CGC G-3'. Briefly, total RNA was isolated from cells using TRIzol reagent ((Thermo Fisher Scientific). First-strand cDNA was synthesized using the Omniscript RT kit (Qiagen, Germany) according to the manufacturer's protocol. SYBR green-based quantitative PCR (qPCR) was performed with Stratagene Mx3000P Real-Time PCR system using Brilliant SYBR Green Master Mix (Stratagene, CA, USA). All reactions were run in triplicates. Data were analyzed with the $2^{-\Delta \Lambda C} T$ method (44). Histone $3 \mathrm{H} 2 \mathrm{a}(\mathrm{HIST} 3 \mathrm{H} 2 \mathrm{~A})$ was used as an internal standard control gene. Statistical significance was determined using Student's t-test after normalizing the expression levels against that of $\mathrm{HIST} 3 \mathrm{H} 2 \mathrm{~A}$ followed by the 
$2^{-\Delta \Delta C} \mathrm{~T}$ method. Differences were considered as statistically significant when $\mathrm{P}$ value was less than $0.05(\mathrm{P}<0.05)$.

\section{Western blot analysis}

Western blot analysis was performed as described previously (45). Briefly, cultured cells were washed, lysed, and centrifuged at $10,000 \times g$ for $15 \mathrm{~min}$. Supernatants were collected and subjected to protein quantification using BCA protein assay (Pierce, IL, USA). Proteins were denatured, separated on SDS-PAGE gels, and transferred onto polyvinylidene difluoride (PVDF) membranes (Millipore, CA). After incubation with antibodies, membranes were developed using SuperSignal West Femto Maximum Sensitivity Substrate (Pierce) and visualized with LAS-3000 luminescent image analyzer (Fuji Photo Film Co., Ltd., Japan).

\section{In vitro capillary tube formation assay}

HUVECs were obtained from the American Type Culture Collection (ATCC, Manassas, VA, USA). The surface of 96-well plates was coated with $25 \mu \mathrm{l}$ Matrigel (BD Biosciences) and allowed to polymerize for $1 \mathrm{~h}$ at $37^{\circ} \mathrm{C}$. HUVECs $\left(5 \times 10^{3}\right.$ cells/well) were seeded onto the surface of Matrigel in SFM containing $1 \% \mathrm{FBS}, 5 \mathrm{ng} / \mathrm{ml}$ basic fibroblast growth factor (bFGF; Thermo Fisher Scientific Inc.), and $2.5 \mathrm{ng} / \mathrm{ml}$ epidermal growth factor (EGF; Thermo Fisher Scientific Inc.). Cells were co-treated with various concentrations of DAA and $200 \mu \mathrm{M}$ $\mathrm{CoCl}_{2}$ for $12-16 \mathrm{~h}$ at $37^{\circ} \mathrm{C}$. Morphological changes and tube formation were photographed under a light microscope.

\section{Chorioallantoic membrane (CAM) assay}

CAM assay was performed as described previously (46). Briefly, fertilized chicken eggs were kept in a humidified incubator at $37^{\circ} \mathrm{C}$ for 4 days. Approximately $4-5 \mathrm{ml}$ of egg albumin was removed with a hypodermic needle, allowing the CAM and yolk sac to drop away from the shell membrane. On day 5 , the shell membrane was peeled away and compoundloaded Thermanox coverslips (NUNC, Rochester, NY) were applied to the CAM surfaces. Two days later, $1 \mathrm{ml}$ of intralipose (Greencross Company, Korea) was injected beneath the CAM. The membrane was observed under a digital camera. Retinoic acid (RA), a well-known anti-angiogenic compound, was used as positive control.

\section{Statistical analysis}

Quantitative values are presented as means \pm standard deviation (SD). Experiments were performed three to five times. Results from one representative experiment are shown. The significance of differences was analyzed using Student's t-test. $P$ value of less than 0.05 was considered as statistically significant.

\section{ACKNOWLEDGEMENTS}

This work was supported by a grant (NRF-2015R1D1A1A
01059808) of the Individual Basic Science \& Engineering Research Program through the National Research Foundation of Korea (NRF) funded by the Korea Government. This work was also supported by a grant from the Cooperative Research Program for Agriculture Science \& Technology Development (Project title: Study of metabolites and new materials for improvement of lifestyle related disease on rice and barley, Project No. PJ00925701) funded by the Rural Development Administration (RDA), Republic of Korea.

\section{REFERENCES}

1. Cairns RA, Harris IS and Mak TW (2011) Regulation of cancer cell metabolism. Nat Rev Cancer 11, 85-95

2. Chang Q, Jurisica I, Do T and Hedley DW (2011) Hypoxia predicts aggressive growth and spontaneous metastasis formation from orthotopically grown primary xenografts of human pancreatic cancer. Cancer Res 71, 3110-3120

3. Graeber TG, Osmanian C, Jacks T et al (1996) Hypoxiamediated selection of cells with diminished apoptotic potential in solid tumours. Nature 379, 88-91

4. Hill RP, Marie-Egyptienne DT and Hedley DW (2009) Cancer stem cells, hypoxia and metastasis. Semin Radiat Oncol 19, 106-111

5. Kioi M, Vogel H, Schultz G, Hoffman RM, Harsh GR and Brown JM (2010) Inhibition of vasculogenesis, but not angiogenesis, prevents the recurrence of glioblastoma after irradiation in mice. J Clin Invest 120, 694-705

6. Pennacchietti S, Michieli P, Galluzzo M, Mazzone $M$, Giordano S and Comoglio PM (2003) Hypoxia promotes invasive growth by transcriptional activation of the met protooncogene. Cancer Cell 3, 347-361

7. Semenza GL (2000) Hypoxia, clonal selection, and the role of HIF-1 in tumor progression. Crit Rev Biochem Mol Biol 35, 71-103

8. Mole DR, Blancher C, Copley RR et al (2009) Genomewide association of hypoxia-inducible factor (HIF)-1alpha and HIF-2alpha DNA binding with expression profiling of hypoxia-inducible transcripts. J Biol Chem 284, 1676716775

9. Xia X, Lemieux ME, Li W et al (2009) Integrative analysis of HIF binding and transactivation reveals its role in maintaining histone methylation homeostasis. Proc Natl Acad Sci U S A 106, 4260-4265

10. Belozerov VE and Van Meir EG (2005) Hypoxia inducible factor-1: a novel target for cancer therapy. Anticancer Drugs 16, 901-909

11. Giaccia A, Siim BG and Johnson RS (2003) HIF-1 as a target for drug development. Nat Rev Drug Discov 2, 803-811

12. Semenza GL (2003) Targeting HIF-1 for cancer therapy. Nat Rev Cancer 3, 721-732

13. Moehler TM, Ho AD, Goldschmidt $\mathrm{H}$ and Barlogie B (2003) Angiogenesis in hematologic malignancies. Crit Rev Oncol Hematol 45, 227-244

14. Folkman J (1971) Tumor angiogenesis: therapeutic implications. N Engl J Med 285, 1182-1186 
15. Onken J, Torka R, Korsing S et al (2016) Inhibiting receptor tyrosine kinase AXL with small molecule inhibitor BMS-777607 reduces glioblastoma growth, migration, and invasion in vitro and in vivo. Oncotarget 7, 9876-9889

16. Paauwe $\mathrm{M}$, Heijkants RC, Oudt $\mathrm{CH}$ et al (2016) Endoglin targeting inhibits tumor angiogenesis and metastatic spread in breast cancer. Oncogene 25, 1-11

17. Placencio VR, Ichimura A, Miyata T and DeClerck YA (2015) Small Molecule Inhibitors of Plasminogen Activator Inhibitor-1 Elicit Anti-Tumorigenic and AntiAngiogenic Activity. PLoS One 10, e0133786

18. Carmeliet $P$ and Jain RK (2011) Molecular mechanisms and clinical applications of angiogenesis. Nature 473, 298-307

19. del Puerto-Nevado L, Rojo F, Zazo S et al (2014) Active angiogenesis in metastatic renal cell carcinoma predicts clinical benefit to sunitinib-based therapy. $\mathrm{Br} J$ Cancer $110,2700-2707$

20. Jang $M H$, Shin $M C, \operatorname{Kim} Y J$, Kim CJ, Kim Y and Kim EH (2004) Atractylodes japonica suppresses lipopolysaccharidestimulated expressions of inducible nitric oxide synthase and cyclooxygenase-2 in RAW 264.7 macrophages. Biol Pharm Bull 27, 324-327

21. Jeong SI, Kim SY, Kim SJ et al (2010) Antibacterial activity of phytochemicals isolated from Atractylodes japonica against methicillin-resistant Staphylococcus aureus. Molecules 15, 7395-7402

22. Kiso $Y$, Tohkin $M$ and Hikino $H$ (1983) Antihepatotoxic principles of Atractylodes rhizomes. J Nat Prod 46, 651-654

23. Satoh K, Nagai F, Ushiyama K and Kano I (1996) Specific inhibition of $\mathrm{Na}+, \mathrm{K}(+)$-ATPase activity by atractylon, a major component of byaku-jutsu, by interaction with enzyme in the E2 state. Biochem Pharmacol 51, 339-343

24. Choi KH, Jeong SI, Lee JH et al (2011) Acetylene compound isolated from Atractylodes japonica stimulates the contractility of rat distal colon via inhibiting the nitrergic-purinergic relaxation. J Ethnopharmacol 134, 104-110

25. Burk D and Schade AL (1956) On respiratory impairment in cancer cells. Science 124, 270-272

26. Conway EM, Collen D and Carmeliet P (2001) Molecular mechanisms of blood vessel growth. Cardiovasc Res 49, 507-521

27. Schuler M and Green DR (2001) Mechanisms of p53dependent apoptosis. Biochem Soc Trans 29, 684-688

28. Semenza GL (1999) Regulation of mammalian O2 homeostasis by hypoxia-inducible factor 1 . Annu Rev Cell Dev Biol 15, 551-578

29. Hatake $K$, Doi T, Uetake $H$, Takahashi $Y$, Ishihara $Y$ and Shirao K (2016) Bevacizumab safety in Japanese patients with colorectal cancer. Jpn J Clin Oncol 46, 234-240

30. Laughner E, Taghavi P, Chiles K, Mahon PC and Semenza GL (2001) HER2 (neu) signaling increases the rate of hypoxia-inducible factor 1alpha (HIF-1alpha) synthesis: novel mechanism for HIF-1-mediated vascular endothelial growth factor expression. Mol Cell Biol 21, 3995-4004

31. Thomas GV, Tran C, Mellinghoff IK et al (2006) Hypoxiainducible factor determines sensitivity to inhibitors of
mTOR in kidney cancer. Nat Med 12, 122-127

32. Westra J, Brouwer E, Bos R et al (2007) Regulation of cytokine-induced HIF-1alpha expression in rheumatoid synovial fibroblasts. Ann N Y Acad Sci 1108, 340-348

33. Jiang BH, Zheng JZ, Aoki M and Vogt PK (2000) Phosphatidylinositol 3-kinase signaling mediates angiogenesis and expression of vascular endothelial growth factor in endothelial cells. Proc Natl Acad Sci U S A 97, 1749-1753

34. Levy AP, Levy NS, Wegner S and Goldberg MA (1995) Transcriptional regulation of the rat vascular endothelial growth factor gene by hypoxia. J Biol Chem 270, 1333313340

35. Yang $Y$, Sun $M$, Wang $L$ and Jiao B (2013) HIFs, angiogenesis, and cancer. J Cell Biochem 114, 967-974

36. Lin M, Hu Y, Chen Y et al (2012) Impacts of hypoxiainducible factor- 1 knockout in the retinal pigment epithelium on choroidal neovascularization. Invest Ophthalmol Vis Sci 53, 6197-6206

37. Zhao W, Wang YS, Hui YN et al (2008) Inhibition of proliferation, migration and tube formation of choroidal microvascular endothelial cells by targeting HIF-1alpha with short hairpin RNA-expressing plasmid DNA in human RPE cells in a coculture system. Graefes Arch Clin Exp Ophthalmol 246, 1413-1422

38. Ruas JL and Poellinger L (2005) Hypoxia-dependent activation of HIF into a transcriptional regulator. Semin Cell Dev Biol 16, 514-522

39. Aebersold DM, Burri P, Beer KT et al (2001) Expression of hypoxia-inducible factor-1alpha: a novel predictive and prognostic parameter in the radiotherapy of oropharyngeal cancer. Cancer Res 61, 2911-2916

40. Unruh A, Ressel A, Mohamed HG et al (2003) The hypoxia-inducible factor- 1 alpha is a negative factor for tumor therapy. Oncogene 22, 3213-3220

41. Choi SW, Son YJ, Yun JM and Kim SH (2012) Fisetin Inhibits Osteoclast Differentiation via Downregulation of p38 and c-Fos-NFATc1 Signaling Pathways. Evidencebased complementary and alternative medicine : eCAM 2012, 810563

42. Choi SW, Moon SH, Yang HJ et al (2013) Antiresorptive activity of bacillus-fermented antler extracts: inhibition of osteoclast differentiation. Evidence-based complementary and alternative medicine : eCAM 2013, 748687

43. Rozen S and Skaletsky H (2000) Primer3 on the WWW for general users and for biologist programmers. Methods Mol Biol 132, 365-386

44. Livak KJ and Schmittgen TD (2001) Analysis of relative gene expression data using real-time quantitative PCR and the 2(-Delta Delta C(T)) Method. Methods (San Diego, Calif.) 25, 402-408

45. Yeon JT, Ryu BJ, Choi SW et al (2014) Natural polyamines inhibit the migration of preosteoclasts by attenuating Ca2 +-PYK2-Src-NFATc1 signaling pathways. Amino Acids 46, 2605-2614

46. Kim KH, Jung $\mathrm{HJ}$ and Kwon HJ (2013) A new antiangiogenic small molecule, G0811, inhibits angiogenesis via targeting hypoxia inducible factor (HIF)-1alpha signal transduction. Biochem Biophys Res Commun 441, 399-404 